\title{
Repeated isolation of tick-borne encephalitis virus from adult Dermacentor reticulatus ticks in an endemic area in Germany
}

\author{
Lidia Chitimia-Dobler ${ }^{1,2}$, Giulia Lemhöfer ${ }^{1}$, Nina Król ${ }^{3}$, Malena Bestehorn², Gerhard Dobler ${ }^{1,2}$ \\ and Martin Pfeffer ${ }^{3 *}$
}

\begin{abstract}
Background: Tick-borne encephalitis (TBE) virus is transmitted to humans and animals through tick bites and is thought to circulate in very strictly defined natural environments called natural foci. The most common tick serving as a vector for the TBE virus in central Europe is /xodes ricinus; it is rarely found in other tick species and in Dermacentor reticulatus it has, so far, only been reported in Poland.

Methods: Between autumn 2016 and spring 2018 ticks were collected by the flagging method in a new TBE focus in the district of northern Saxony, Germany, outside the known risk areas as defined by the national Robert Koch Institute. Ticks were morphologically identified and tested in pools for the presence of TBE virus using a real-time RT-PCR. TBE virus from positive pools was isolated in A549 cells, and the E gene sequences were determined after conventional RT-PCR, followed by a phylogenetic comparison.

Results: TBE virus was detected in 11 pools, 9 times in flagged adults D. reticulatus ( $n=1534$; MIR: 0.59\%, Cl: $0.29-$ $11.3 \%$ ) and only twice in I. ricinus nymphs ( $n=349 ;$ MIR: $0.57 \%, \mathrm{Cl}: 0.02-2.2 \%)$. All other ticks, I. ricinus males $(n=33)$, females ( $n=30$ ) and larvae $(n=58)$, as well as 5 I. inopinatus ( 2 females, 3 males) and 14 Haemaphysalis concinna (3 females, 11 nymphs), tested negative for TBE virus. TBE virus was not detected in I. ricinus during the summer, when $D$. reticulatus is not active. Sequence comparison of the entire $E$ gene of the isolated virus strains resembled each other with only 3 nucleotide differences. The most closely related viral sequences belong to TBE virus strains from Poland and Neustadt an der Waldnaab (county of Neustadt an der Waldnaab, Bavaria), approximately 200 km east and 200 $\mathrm{km}$ south-west of the new focus, respectively.
\end{abstract}

Conclusions: TBE virus was found in northern Saxony, Germany, with similar MIRs in D. reticulatus and I. ricinus, indicating that $D$. reticulatus plays an equal role to I. ricinus in virus circulation when both tick species are sympatric.

Keywords: Dermacentor reticulatus, TBE virus, Saxony, Germany

\section{Background}

Tick-borne encephalitis (TBE) virus (genus Flavivirus, family Flaviviridae) is the etiological agent of TBE, the medically most important member of the tick-borne serocomplex [1]. At present, three subtypes of TBE virus are recognized: the European (western) subtype

\footnotetext{
*Correspondence: pfeffer@vetmed.uni-leipzig.de

${ }^{3}$ Institute of Animal Hygiene and Veterinary Public Health, Faculty of Veterinary Medicine, University of Leipzig, An den Tierkliniken 1, 04103 Leipzig, Germany

Full list of author information is available at the end of the article
}

(TBEV-EU), the Siberian subtype (TBEV-Sib) and the Far-Eastern subtype (TBEV-FE) [2]. Russian virologists have claimed two new subtypes, both isolated in the Lake Baikal region in Siberia, which are genetically more distant to each of the three currently accepted TBE virus subtypes [3].

Of the 54 species of ixodid ticks known from the western Palaearctic [4], eight species from three genera are known to be able to transmit TBE virus, and so far the virus has been isolated from at least 14 other species (see references in [5]). Ixodes ricinus, the most commonly 
encountered European tick species, is considered to be the major vector of the European TBE virus $[6,7]$. Lichard \& Kozuch [8] were able to show TBE virus persistence and transmission to white mice by Ixodes arboricola, which is considered to be a secondary amplifying vector of TBE virus in wild rodent populations [9]. Ixodes persulcatus is the main vector tick species known to transmit TBEV-Sib and TBEV-FE [10]. Haemaphysalis concinna is also a known vector of TBE virus $[11,12]$. Nosek et al. [13] experimentally proved the vector competence of Haemaphysalis inermis for TBE virus. Ixodes gibbosus is a marginal vector in the Mediterranean region [14]. In addition, TBE virus has been found in other tick species but transmission has not been demonstrated, for example in Ixodes frontalis $[10,15,16]$. The virus has been isolated in the Czech Republic from females and nymphs of $I$. hexagonus infesting a hedgehog [17], as well as in Croatia from a pool of three females removed from a red fox [18]. Haemaphysalis punctata has also been associated with TBE virus [19].

The genus Dermacentor (family Ixodidae) includes 35 species and has a worldwide distribution, except for Australia [20]. Dermacentor species are found mostly in Europe, Asia and North America [21]. In Europe, two species, $D$. reticulatus ('the ornate dog tick') and D. marginatus ('the ornate sheep tick'), as well as one in Asia, $D$. nuttalli, are associated with TBE virus. Both D. marginatus and D. reticulatus are competent vectors of this virus [22-24]. The role of Dermacentor ticks in the circulation of TBE virus in the environment is, however, unclear and poorly studied [25, 26]. Dermacentor reticulatus appears to be spreading and its distribution area and its population density have been increasing during recent decades [25-29]. In eastern Poland, the average prevalence of infection with TBE virus found in D. reticulatus was $10.8 \%$, which is considerably higher than the prevalence found in $I$. ricinus (1.6\%) [30]. The prevalence rate in $D$. reticulatus ticks from Białowieża Primeval Forest was similar (1.58\%) [31] to that in I. ricinus (1.3\%) [32], which is in line with the case from Moldova (I. ricinus, 3.8\%; D. reticulatus, 3.9\%; but Haemaphysalis punctata, 8.8\%) [33]. However, the dynamics of TBE virus in the D. reticulatus tick population in TBE natural foci has not been studied so far and no data on TBE virus circulation in $D$. reticulatus in central Europe are available.

Every active tick stage can be infected with TBE virus [34], and approximately $0.1-5 \%$ of the ticks in an endemic area carry the virus [6]. As larvae and nymphs of $D$. reticulatus are nidicolous and adults exophilic (nonnidicolous), only the female $D$. reticulatus ticks are considered to play a major role in the virus transmission to larger mammals including humans, while in case of $I$. ricinus, the nymph is the key stage in viral transmission.
Tick males, which either do not feed at all or parasitize only for a short time, might also be involved in virus transmission. Investigations of the viral load of either nymphs, female or male ticks from German natural foci by means of quantitative real-time RT-PCR did not show any significant differences in virus load between the respective stages and sexes (Dobler et al., unpublished results). However, in a Russian study the researchers stated that male ticks appear to be responsible mainly for asymptomatic infections because of their lower virus load and short time of sucking, and thus can contribute to host and population immunity [35]. TBE virus invades all tick tissues, including the salivary glands and ovaries [36], thus it may be transmitted in various ways: (i) take up of the virus during viremia of the host; (ii) via co-feeding (direct uptake of the virus from one tick feeding on a non-viremic host in close proximity to a tick harboring the virus); (iii) transstadial, (from one life stage to the next life stage after molting); (iv) transovarial (vertical from female tick to her eggs); (v) transsexual (between male and female during mating on the host); and (vi) infection of the next host via saliva (reviewed in [5]).

In this study we describe a new natural TBE focus in Germany and the phenology of TBE virus in D. reticulatus for a period of three seasons.

\section{Methods}

Study site

In July 2016, the first ever human TBE case was reported from the district Northern Saxony in the German Federal State of Saxony, so far classified as a TBE non-endemic area (Fig. 1). The exact location where the infection most likely took place could be identified with the patient's information. The landscape is dominated by a rather young mixed forest consisting of birch, oak, maple and pine trees, the latter up to 80 years-old, while the deciduous trees are mostly younger than 20 years of age. In the undergrowth, blueberries, blackberries and raspberries can be found. The forest is interrupted by patches of meadow and surrounded by larger stretches of agricultural land. The nearest human settlement is a small village (Battaune), which is about $500 \mathrm{~m}$ away; no industrial areas or waste disposal sites are located within this area. Only a small area surrounding a demolished house is used as illegal dump site for household trash. There are 11 rather large areas of livestock holdings within a radius of approximately $1 \mathrm{~km}$ of the flagging area.

\section{Tick collection and identification}

All specimens were collected as questing ticks by flagging as part of a tick-borne encephalitis (TBE) programme in Battaune, Federal State of Saxony, Germany, at the end of September 2016, in February, April, July and September 


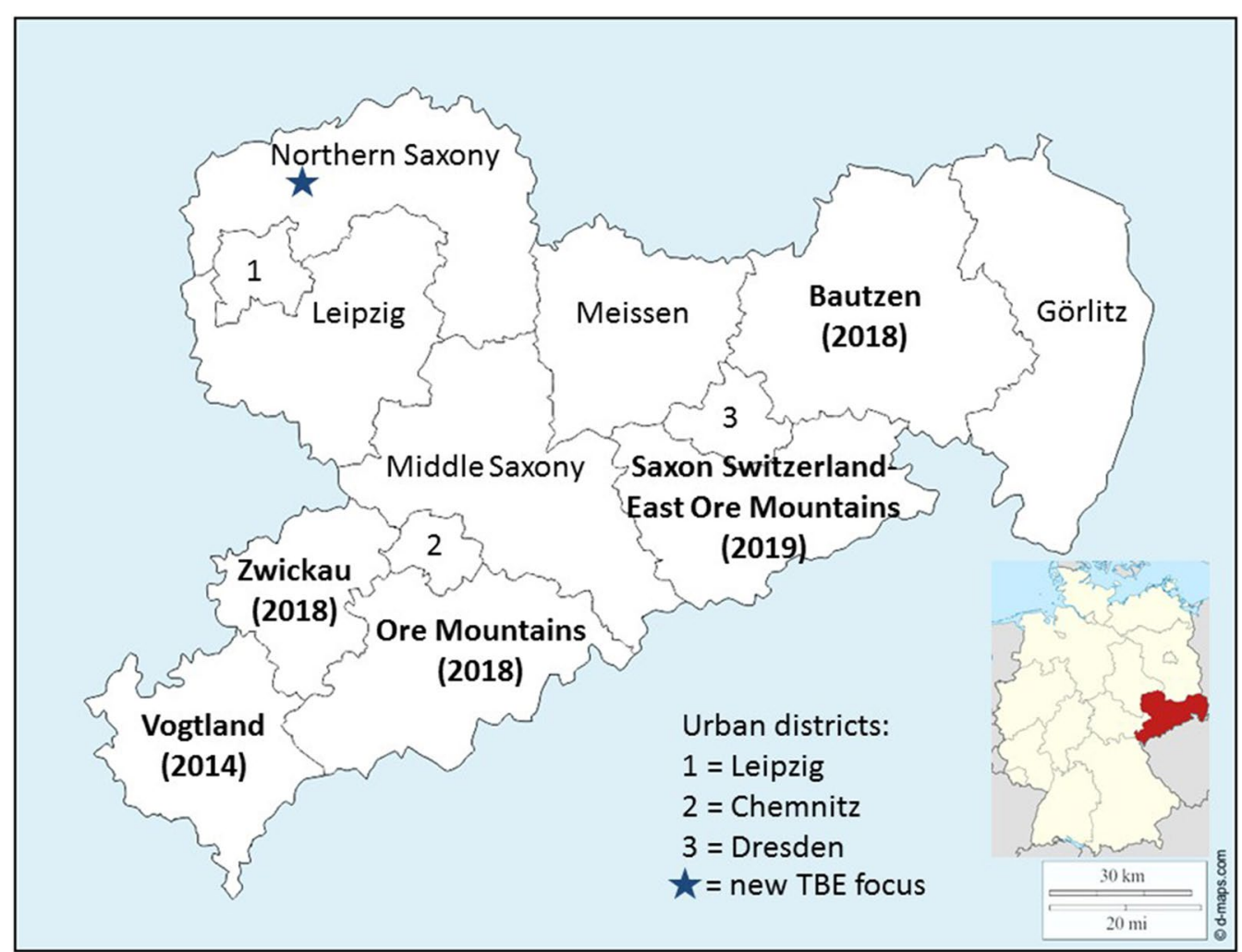

Fig. 1 A map of Saxony showing all counties. Names of counties considered as TBE risk area according to the federal Robert Koch Institute are named with bold lettering showing the year since they were considered TBE risk area in parentheses. The new TBE focus described here is indicated by an asterisk. At the time of our study it was about $150 \mathrm{~km}$ north of the next known risk area

2017, and April 2018. The ticks were kept alive in $50 \mathrm{ml}$ plastic tubes until identification and further testing in the laboratory. Ticks were identified to species level using the morphological characters according to Feider [37], Filippova [38] and Estrada-Peña et al. [39].

\section{Nucleic acid extraction and PCR}

Ticks were processed in pools of 10 nymphs or 5 adults (females or males) per pool. Ticks were homogenized using $1 \mathrm{ml}$ minimum essential medium (MEM, Invitrogen, Karlsruhe, Germany) containing an antibiotic-antimycotic solution (ABAM, Invitrogen) using a Fast Prep Savant FP120 tissue lyser (Bio101, Vista, USA), with three rounds at speed 6.5 for $30 \mathrm{~s}$ each. Total nucleic acid was extracted using the MagNA Pure LC RNA/DNA Kit (Roche, Mannheim, Germany) in a MagNA Pure LC instrument (Roche, Mannheim, Germany) according to the manufacturer's instructions using $200 \mu \mathrm{l}$ of the tick homogenate. The total nucleic acid was extracted in $50 \mu \mathrm{l}$ and a $5 \mu \mathrm{l}$ aliquot was tested for TBE virus RNA using real-time RT-PCR (RT-qPCR; [40]).

\section{Virus isolation}

A $100 \mu$-aliquot of the supernatants of each crushed RT-qPCR-positive tick pool was added to an $80 \%$ confluent cell culture of A549 cells (human lung carcinoma cells, German Collection of Microorganisms and Cell Cultures, DSMZ, Braunschweig). The supernatants were kept at $-80{ }^{\circ} \mathrm{C}$ until they were used undiluted and in a dilution of 1:5 and 1:10 for virus isolation. After $1 \mathrm{~h}$ of incubation at $37^{\circ} \mathrm{C}$, the supernatant was pipetted off and the cells were washed 5 times with MEM containing ABAM. Five milliliters of MEM containing 5-fold concentrated ABAM and $3 \%$ fetal calf serum were added. Cells were incubated for up to 7 days at $37^{\circ} \mathrm{C}$ and observed daily for the occurrence of cytopathogenic effect (cpe). In case of more than $50 \%$ cpe, the supernatant was taken and tested by RTqPCR for TBEV as described. In case of no cpe, culture supernatant was taken after 7 days of incubation and also tested for growth of TBEV by RT-qPCR. No subcultures were conducted. From the isolated TBEV strains E genes were sequenced for confirmation (see below). 


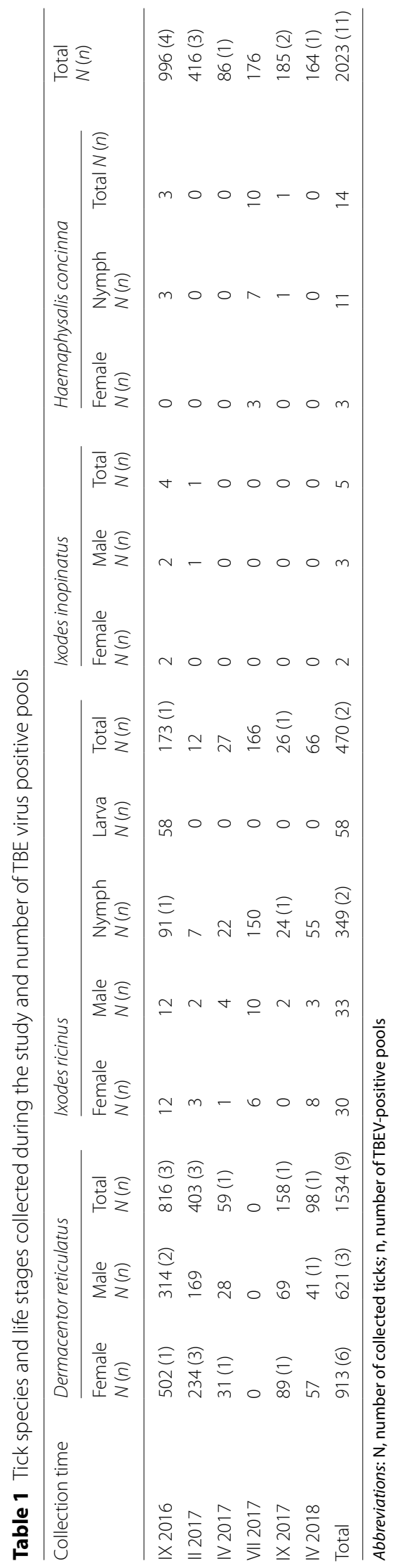




\section{Sequence analyses of TBE virus E-gene}

The E-gene was amplified with a conventional PCR directly from positive tick nucleic acid extractions [41]. This RT-PCR amplified a $1687 \mathrm{bp}$ fragment which was then sequenced using the outer primers and an additional internal sequencing primer as described previously [41]. The products were purified after gel electrophoresis and processed as described [42]. All sequence data were processed using the program Geneious v.9.1.5. A de novo assembly was performed using the three chromatograms obtained from GATC (Eurofins Genomics, Ebersberg, Germany) for each positive sample. Nucleotides with an estimated error higher than $1 \%$ were trimmed. Subsequently the sequences were cut to $1488 \mathrm{bp}$, the exact length of the envelope gene sequence. A ClustalW alignment with several other $E$ genes from selected isolates was performed and a phylogenetic tree was generated using the PhyML algorithm [43].

\section{Statistical analyses}

The minimum infection rate (MIR) was calculated for pools of 10 nymphs or 5 adults. It was assumed that only one tick specimen in the pool was infected if the pool tested positive. Fisher's test was used to compare the prevalence levels for significant independence using GraphPad Prism v.4 (Graph Pad Software, San Diego, CA, USA). The significance threshold was set at $P=0.05$. Confidence intervals $(95 \% \mathrm{CI})$ for the prevalence of pathogens were determined by the modified Wald method.

\section{Results}

Overall, 2023 ticks belonging to four species (Dermacentor reticulatus, Ixodes ricinus, I. inopinatus and Haemaphysalis concinna) were collected by flagging (Table 1 ). In September 2016, 996 ticks were collected during 3 consecutive days: 816 D. reticulatus (502 females and 314 males); 173 I. ricinus (12 females, 12 males, 91 nymphs and 58 larvae); 4 I. inopinatus (2 females and 2 males) and $3 \mathrm{H}$. concinna nymphs. Of the 174 pools, TBE viral RNA was detected in 3 pools of $D$. reticulatus ( 1 female and 2 male pools) and 1 I. ricinus nymph pool.

In 2017, 863 ticks were collected during the year, from which 620 D. reticulatus (266 males and 354 females), 231 I. ricinus (18 males, 10 females and 203 nymphs), one I. inopinatus (male), and $11 \mathrm{H}$. concinna (3 females and 8 nymphs) were identified. Details regarding tick species activity are presented in Table 1 . From specimens collected in February, 90 pools were tested and 3 D. reticulatus female pools were positive. From ticks sampled in April, 16 pools were tested: 12 D. reticulatus pools and 4 I. ricinus pools, with $1 D$. reticulatus female positive pool. From ticks from July, 27 pools were analysed: 22 I. ricinus pools and $2 \mathrm{H}$. concinna nymph pools and 3 individual females, none of which were positive. From individuals collected in September, 38 pools were investigated and 2 pools were positive, $1 \mathrm{D}$. reticulatus female pool and $1 \mathrm{I}$. ricinus nymph pool.

In April 2018, 164 ticks were collected: 98 D. reticulatus (41 males and 57 females) and 66 I. ricinus ( 3 males, 8 females and 55 nymphs). Of 33 pools, one male $D$. reticulatus pool was positive.

In total, the detection of viral RNA in 11 tick pools was confirmed by the isolation of virus strains from 3 male and 6 female D. reticulatus pools and two pools of I. ricinus nymphs.

In general, the minimum infection rate (MIR) for $D$. reticulatus was $0.59 \%$ (CI: $0.29-11.3 \%$ ) and $0.42 \%$ (CI: $0.01-1.64 \%$ ) for I. ricinus ticks and $0.57 \%$ (CI: $0.02-2.2 \%$ ) for $I$. ricinus nymphs. There were no statistical differences in the TBE prevalence between $D$. reticulatus ticks and $I$. ricinus nymphs $(P=1.000)$ or ticks $(P=1.000)$. The tested $I$. ricinus ticks were all negative in July 2017 when $D$. reticulatus ticks were entirely absent.

A total of $11 \mathrm{E}$-genes sequences from the positive tick pools were generated and analysed. The phylogenetic tree is shown in Fig. 2. The analysis showed that all virus strains belong to one single genetic cluster of TBE virus. Phylogenetic analysis of the $E$ gene sequences with other available $E$ genes from TBE virus strains of different geographical areas in Europe exhibited a close relationship to TBE E-gene sequences from Poland, southern Germany and Switzerland. The virus strains from $D$. reticulatus ticks showed no difference to virus strains from I. ricinus ticks from the focus and from other foci (strain NW-2A111 from I. ricinus from Germany; RG18 from I. ricinus from Poland, 1971). The actual sequences of the $E$ genes were also closely related to sequences from Germany (2011) and from Poland (1971).

\section{Discussion}

TBE virus was detected and isolated repeatedly from D. reticulatus during three sampling seasons in an area of sympatric occurrence together with I. ricinus and, to a lesser extent, I. inopinatus and H. concinna. Although TBE viral RNA has previously been detected in D. reticulatus ticks [30-32] and its capability of transmitting TBE virus has been demonstrated [13], this was a surprising finding. The maintenance of TBE virus by $D$. reticulatus in natural foci in the absence of Ixodes ticks was considered highly unlikely [44]; however, $D$. reticulatus was considered to support TBE virus circulation in the presence of I. ricinus populations. Our results suggest the opposite, i.e. that $D$. reticulatus is at least of equal importance in the maintenance of TBE virus in this natural focus as (i) we found it throughout our sampling period and (ii) the virus was absent in the I. ricinus population 


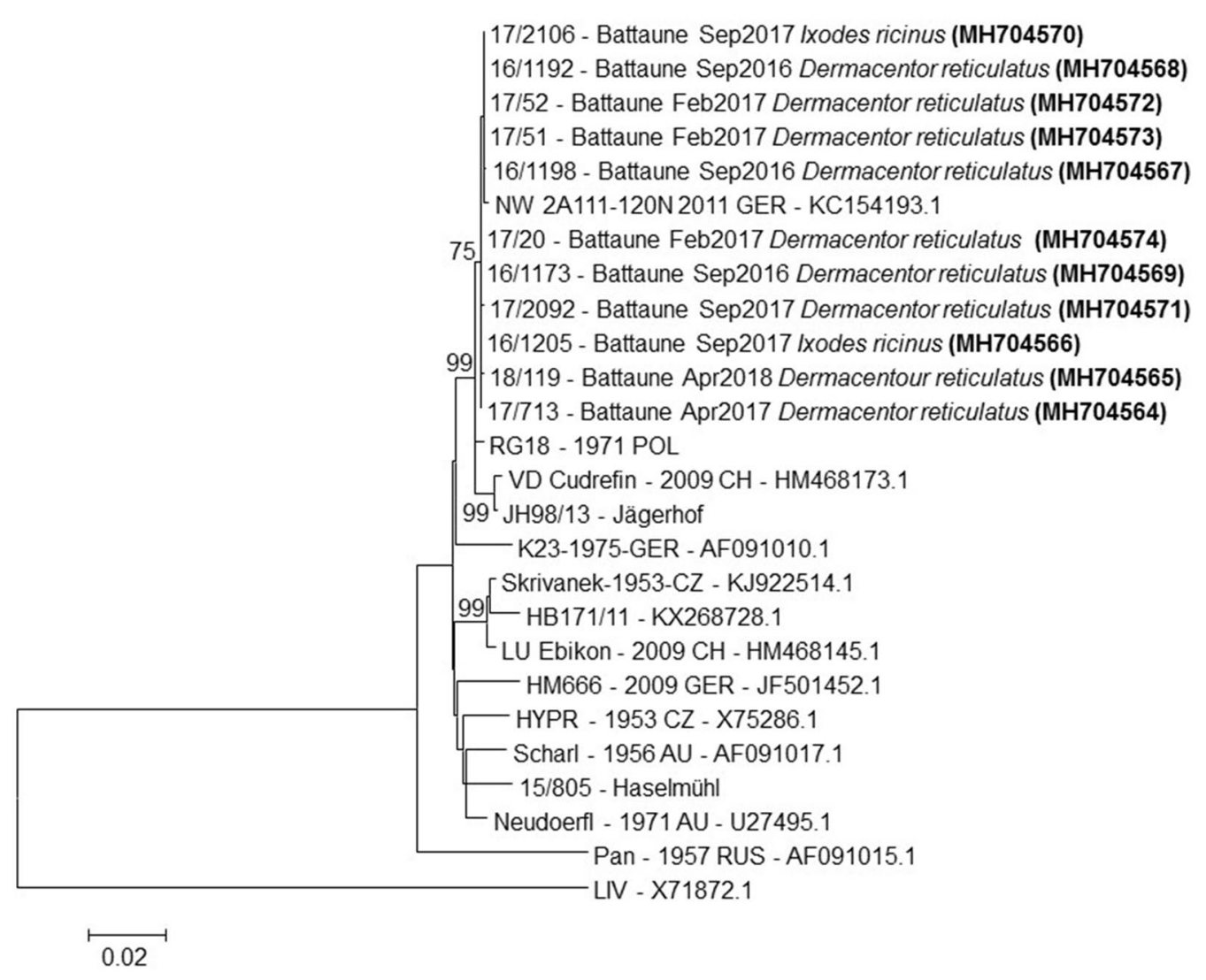

Fig. 2 Phylogenetic analysis of complete E gene sequences of European TBE virus strains using louping ill virus (LIV) as outgroup. Nucleotide sequences generated for this manuscript are given in bold and the name of the respective tick species is provided. The countries of origin are given as: GER, Germany; CZ, Czech Republic; AU, Austria; CH, Switzerland; POL, Poland; RUS, Russia. GenBank accession numbers are also provided

during the summer when adult $D$. reticulatus cannot be flagged (see below).

In European parts of Russia where D. reticulatus sympatrically occurs with $I$. persulcatus, a genetically closely related species to I. ricinus, the virus was also found in both tick species [45]. In contrast to the situation described here, the authors found a sympatric occurrence of D. reticulatus and I. persulcatus throughout the year while in Germany, as in central Europe, $D$. reticulatus adults do not quest and thus cannot be collected by flagging in summer $[28,46,47]$. Recent reports from Poland support our findings, where TBE virus was detected in $10.8 \%$ of $148 \mathrm{D}$. reticulatus and in only $1.6 \%$ of 875 I. ricinus [30]. As immature stages of all these tick species can feed on the same host at the same time, infection may occur on viremic rodents or during cofeeding on the same small mammal as demonstrated in Udmurtia [45]. As transstadial transmission was also previously demonstrated for $D$. reticulatus [36], the most likely source of the TBE virus infection of these nidicolous immatures are rodents, mainly mice of the genus Apodemus and the bank vole (Myodes glareolus), known to serve as reservoir hosts for TBE virus $[34,36]$. Future attempts must investigate the role of small mammals in the TBE virus transmission cycle at this natural focus. However, the detection and isolation of TBE virus in Dermacentor tick species is not very common and the reasons for this are neither known nor understood. The repeated findings of TBE virus positive $D$. reticulatus ticks in three consecutive years, 2016-2018, are notable. It may be speculated that because TBE virus has been recently introduced into this area (as no human TBE case has been reported in this region since 2001 when TBE became a notifiable disease in Germany), it seems very likely that the most abundant tick species became the main carrier of the virus.

It is interesting to note that positive I. ricinus nymphs were found only in September, when both I. ricinus and $D$. reticulatus activity was high. To explain if this was an accidental occurrence, more studies should be conducted. However, the positive testing of TBE virus might possibly support the theory that the tick species 
D. reticulatus plays a major part in the conservation of this TBE natural focus. This would be consistent with the findings of the Polish research team of Biernat et al. [31] in Poland. This is also mirrored by the equal MIR of $D$. reticulatus and $I$. ricinus nymphs with $0.59 \%$ and $0.57 \%$, respectively. Interestingly the total (nymph and adults) $I$. ricinus MIR of $0.42 \%$ was very similar to $0.47 \%$ found in a recent study investigating the prevalence of TBE virus in the upper Rhine region in 2016-2017, more than $500 \mathrm{~km}$ away from the TBE focus investigated here [48].

In contrast to this study, where only two $\mathrm{E}$ gene sequences were identical [48], our phylogenetic analyses did not reveal a striking difference between nucleotide sequences derived from either $D$. reticulatus or $I$. ricinus ticks. The branching of our sequences together with sequences from Poland (approximately $200 \mathrm{~km}$ east) and Neustadt an der Waldnaab (approximately $200 \mathrm{~km}$ southwest) are in line with a general east to west evolution of TBE viruses [49], but they do not provide hints why $D$. reticulatus seems to be the key vector in TBE virus maintenance in this natural focus. The phylogenetic analyses of the E genes show a marked high homology to virus strains from Poland isolated in 1971 and from Germany isolated in 2011. It is surprising that the virus did not show mutations during this long time period. It might be an indication of a rather recent introduction from Poland or South Germany. The data also show that there is so far no adaptation of the TBE strain to different tick species belonging to different tick genera. Dermacentor and Ixodes separated more than 200 million years ago and therefore are genetically very distant. One would expect that an RNA virus would adapt to such different vectors and reservoirs. The TBE virus detections in $D$. reticulatus in Poland showed a sequence in the $C$ gene, which the Polish group interpreted as specific for the tick species $D$. reticulatus. We did not investigate the $C$ gene as the $E$ gene is thought to be more informative with regards to virus strain separation [49]. The lack of differences in the E genes of the virus strains from different tick species might, however, also be indicative of a recent introduction of this strain into the population of $D$. reticulatus. It will be interesting to follow the genetic evolution of this virus strain during the next years to show whether changes will be introduced in the genome of the virus specific for $D$. reticulatus ticks.

\section{Conclusions}

TBE virus was detected in Dermacentor reticulatus ticks throughout their activity season and only occasionally in Ixodes ricinus sharing the same area in sympatry. In the warm summer months when adult D. reticulatus are not questing and thus cannot be flagged, the virus was not found in active I. ricinus of any life stage, further supporting the conclusion that $D$. reticulatus may play an important role in virus circulation in this newly established TBE focus.

\begin{abstract}
Abbreviations
ABAM: antibiotic-antimycotic; AU: Austria; C: capsid; cpe: cytopathogenic effect; CH: Switzerland; CZ: Czech Republic; E: envelope; GER: Germany; LIV: louping ill virus; MEM: minimum essential medium; MIR: minimum infection rate; $\mathrm{POL}$ : Poland; RNA: ribonucleic acid; RUS: Russia; RT-PCR: reverse transcription-polymerase chain reaction; RT-qPCR: reverse transcriptasequantitative polymerase chain reaction; TBE: tick-borne encephalitis; TBEV: tickborne encephalitis virus; TBEV-EU: European (western) subtype of tick-borne encephalitis virus; TBEV-Sib: Siberian subtype of tick-borne encephalitis virus; TBEV-FE: Far-Eastern subtype of tick-borne encephalitis virus.
\end{abstract}

\section{Acknowledgements}

Many thanks go to Yauhen Karliuk, Hannah Schmuck and Anna Obiegala for their help with field work. Funding by the German Ministry of Research and Education (BMBF) and Pfizer Pharma GmbH are highly appreciated. We acknowledge support from the German Research Foundation (DFG) and Leipzig University within the programme of Open Access Publishing.

\section{Funding}

This study was funded by the German Ministry of Research and Education (BMBF) network project TBENAGER (FKZ 01KI1728D) and Pfizer Pharma GmbH, Berlin, project-no. WI211158 "Characterization of TBE viruses from Saxony".

\section{Availability of data and materials}

Sequence data of E-genes have been deposited in the GenBank database under the accession numbers MH704564-MH704574. TBE virus strains isolated during this study are part of the virus strain collection at the National Consiliar Laboratory on TBE in Munich headed by GD. Virus material will be made available upon request and after proof of BSL3 conditions of the receiving institute.

\section{Authors' contributions}

All authors participated in the field work of tick collection. LCD, GL and MB carried out the morphological identification and nucleic acid extraction of the ticks, and the molecular analyses. GL and MB carried out the phylogenetic analyses. GD performed the virus isolation. NK performed the statistical analysis. LCD, GD and MP analyzed and assembled the data, and wrote the manuscript draft. All authors read and approved the final manuscript.

Ethics approval and consent to participate

Not applicable.

Consent for publication

Not applicable.

\section{Competing interests}

The authors declare that they have no competing interests.

\section{Publisher's Note}

Springer Nature remains neutral with regard to jurisdictional claims in published maps and institutional affiliations.

\section{Author details \\ ${ }^{1}$ Bundeswehr Institute of Microbiology, Neuherbergstrasse 11, 80937 Munich, Germany. ${ }^{2}$ Parasitology Unit, University of Hohenheim, Emil-Wolff-Str. 35, 70599 Stuttgart, Germany. ${ }^{3}$ Institute of Animal Hygiene and Veterinary Public Health, Faculty of Veterinary Medicine, University of Leipzig, An den Tierklini-} ken 1, 04103 Leipzig, Germany.

Received: 1 October 2018 Accepted: 26 February 2019

Published online: 12 March 2019

References

1. Gould EA, Solomon T. Pathogenic flaviviruses. Lancet. 2008;371:500-9. 
2. Ecker M, Allison SL, Meixner T, Heinz FX. Sequence analysis and genetic classification of tick-borne encephalitis viruses of Europe and Asia. J Gen Virol. 1999:80:179-85.

3. Pukhovskaya NM, Morozova OV, Vysochina NP, Belozerova NB, Bakhemtyeva SV, Zdanovskaya NI, et al. Tick-borne encephalitis virus in arthropod vectors in the far east of Russia. Ticks Tick Borne Dis. 2018;9:824-33.

4. Estrada-Peña A, Nava S, Petney T. Ticks of Europe and North Africa: a guide to species identification. Cham, Switzerland: Springer; 2017.

5. Chitimia-Dobler L, Mackenstedt U, Petney TN. Transmission/Natural cycle. In: Dobler G, Erber W, Schimitt H-J, editors. Tick-borne Encephalitis (TBE). Singapore: Globel Health Press Pte Ltd; 2018. p. 41-57.

6. Süss J. Epidemiology and ecology of TBE relevant to the production of effective vaccines. Vaccine. 2003;21:S19-35.

7. Rizzoli A, Silaghi C, Obiegala A, Rudolf I, Hubálek Z, Földvári G, et al. Ixodes ricinus and its transmitted pathogens in urban and peri-urban areas in Europe: new hazards and relevance for public health. Front Public Health. 2014;2:251.

8. Lichard M, Kozuch O. Persistence of tick-borne encephalitis virus in nymphs and adults of Ixodes arboricola and its transmission to white mice. Acta Virol. 1967;11:480.

9. Gresíková M, Kaluzová M. Biology of tick-borne encephalitis virus. Acta Virol. 1997:41:115-24

10. Labuda M, Nuttall PA. Tick-borne viruses. Parasitology. 2004;129:S221-45.

11. Kozuch O, Nosek T. Experimental transmission of tick-borne encephalitis (TBE) virus by Haemaphysalis concinna ticks. Acta Virol. 1980;24:377.

12. Khazova T, lastrebov V. Combined focus of tick-borne encephalitis, tick-borne rickettsiosis and tularemia in the habitat of Haemaphysalis concinna in south central Sibiria. Zh Mikrobiol Epidemiol Immunobiol. 2001;1:78-80 (In Russian)

13. Nosek J, Ciampor F, Kozuch O, Rajcani J. Localization of tick-borne encephalitis virus in alveolar cells of salivary glands of Dermacentor marginatus and Haemaphysalis inermis ticks. Acta Virol. 1972;16:493-7.

14. Hubálek Z, Rudolf I. Tick-borne viruses in Europe. Parasitol Res. 2012;111:9-36

15. Hillyard P. Ticks of North-West Europe. London: Linnean Society; 1996.

16. Obsomer V, Wirtgen M, Linden A, Claerebout E, Heyman P, Heylen D, et al. Spatial disaggregation of tick occurrence and ecology at a local scale as a preliminary step for spatial surveillance of tick-borne diseases: general framework and health implications in Belgium. Parasit Vectors. 2013;6:190.

17. Krivanec K, Kopecky E, Tomkova E, Grubhoffer L. Isolation of TBE virus from the tick Ixodes hexagonus. Folia Parasitol (Praha). 1988;35:273-6.

18. Jemeršić L, Dežđek D, Brnić D, Prpić J, Janicki Z, Keros T, et al. Detection and genetic characterization of tick-borne encephalitis virus (TBEV) derived from ticks removed from red foxes (Vulpes vulpes) and isolated from spleen samples of red deer (Cervus elaphus) in Croatia. Ticks Tick Borne Dis. 2014;5:7-13.

19. Hubálek Z, Juricová Z, Halouzka J, Pellantová J, Hudec K. Arboviruses associated with birds in southern Moravia, Czechoslovakia. Acta Sc Nat Brno. 1989;7:1-50

20. Guglielmone A, Robbins R, Apanaskevich D, Petney T, Estrada-Peña A, Horak I. The hard ticks of the world (Acari: Ixodida: Ixodidae). Dordrecht: Springer; 2014.

21. Nicholson W, Sonenshine D, Lane R, Uilenberg G. Ticks (Ixodida). In: Mullen G, Durden L, editors. Medical and veterinary entomology. 2nd ed. Burlington, San Diego, London: Elsevier; 2009. p. 483-533.

22. Hoogstraal $\mathrm{H}$. Ticks in relation to human diseases caused by viruses. Ann Rev Entomol. 1966;11:261-308.

23. Kožuch O, Nosek J. Transmission of tick-borne encephalitis (TBE) virus by Dermacentor marginatus and D. reticulatus ticks. Acta Virol. 1971;15:334.

24. Nosek J. The ecology and public health importance of Dermacentor marginatus and D. reticulatus ticks in central Europe. Folia Parasitol (Praha). 1972;19:93-102

25. Karbowiak G. The occurrence of the Dermacentor reticulatus tick - its expansion to new areas and possible causes. Ann Parasitol. 2014;60:37-47.

26. Karbowiak G, Kiewra D. New locations of Dermacentor reticulatus ticks in western Poland: the first evidence of the merge in D. reticulatus occurrence areas? Wiad Parazytol. 2010;56:333-6.

27. Dautel H, Dippel C, Oehme R, Hartelt K, Schettler E. Evidence for an increased geographical distribution of Dermacentor reticulatus in
Germany and detection of Rickettsia sp. RpA4. Int J Med Microbiol. 2006:40:149-56.

28. Chitimia-Dobler L. Spatial distribution of Dermacentor reticulatus in Romania. Vet Parasitol. 2015;214:219-23.

29. Rubel F, Brugger K, Pfeffer M, Chitimia-Dobler L, Didyk YM, Leverenz S, et al. Geographical distribution of Dermacentor marginatus and Dermacentor reticulatus in Europe. Ticks Tick Borne Dis. 2016;7:224-33.

30. Wojcik-Fatla A, Cisak E, Zając V, Zwoliński J, Dutkiewicz J. Prevalence of tick-borne encephalitis virus in Ixodes ricinus and Dermacentor reticulatus ticks collected from the Lublin region (eastern Poland). Ticks Tick Borne Dis. 2011;2:16-9.

31. Biernat B, Karbowiak G, Werszko J, Stańczak J. Prevalence of tick-borne encephalitis virus (TBEV) RNA in Dermacentor reticulatus ticks from natural and urban environment, Poland. Exp Appl Acarol. 2014;64:543-51.

32. Biernat B, Karbowiak G, Stańczak J, Masny A, Werszko J. The first detection of the tick-borne encephalitis virus (TBEV) RNA in Dermacentor reticulatus ticks collected from the lowland European bison (Bison bonasus bonasus L.). Acta Parasitol. 2016;61:130-5.

33. Ponomareva EP, Mikryukova TP, Gori AV, Kartashov MY, Protopopova EV, Chausov EV, et al. Detection of Far-Eastern subtype of tick-borne encephalitis viral RNA in ticks collected in the Republic of Moldova. J Vector Borne Dis. 2015;52:334-6.

34. Karbowiak G, Biernat B. The role of particular tick developmental stages in the circulation of tick-borne pathogens affecting humans in central Europe. 2. Tick-borne encephalitis virus. Ann Parasitol. 2016;62:3-9.

35. Korenberg El, Ivanova LM, Yurkova EV. Changes of epidemic manifestation of tick-borne encephalitis in a natural focus. Med Parazitol. 1986;2:35-9 (In Russian).

36. Karbowiak G, Biernat B, Werszko J, Rychlik L. The transstadial persistence of tick-borne encephalitis virus in Dermacentor reticulatus ticks in natural conditions. Acta Parasitol. 2016;61:201-3.

37. Feider Z. Arachnida, Acaromorpha, Suprafamily Ixodoidea (Ticks). In: Fauna of the People's Republic of Romania. Bucharest: Ed. Academiei Republicii Populare Romane; 1965 (In Romanian).

38. Filippova NA. Ixodid ticks (Ixodinae). Fauna USSR new series 4(4). Moscow-Leningrad: Nauka; 1977 (In Russian).

39. Estrada-Peña A, Nava S, Petney T. Description of all the stages of Ixodes inopinatus n. sp. (Acari: Ixodidae). Ticks Tick Borne Dis. 2014;5:734-43.

40. Schwaiger M, Cassinotti P. Development of a quantitative real-time RTPCR assay with internal control for the laboratory detection of tick-borne encephalitis virus (TBEV) RNA. J Clin Virol. 2003;27:136-45.

41. Kupča AM, Essbauer S, Zoeller G, de Mendonça PG, Brey R, Rinder M, et al. Isolation and molecular characterization of a tick-borne encephalitis virus from a new tick-borne encephalitis focus with severe cases in Bavaria, Germany. Ticks Tick Borne Dis. 2010;1:44-51.

42. Frey S, Mossbrugger I, Altantuul D, Battsetseg J, Davaadorj R, Tserennorov D, et al. Isolation, preliminary characterization, and full-genome analyses of tick-borne encephalitis virus from Mongolia. Virus Genes. 2012;45:413-25.

43. Guindon S, Dufayard JF, Lefort V, Anisimova M, Hordijk W, Gascuel O. New algorithms and methods to estimate maximum-likelihood phylogenies: assessing the performance of PhyML 3.0. Syst Biol. 2010;59:307-21.

44. Katargina O, Russakova S, Geller J, Kondrusik M, Zajkowska J, Zygutiene $M$, et al. Detection and characterization of tick-borne encephalitis virus in Baltic countries and eastern Poland. PLoS One. 2013;8:e61374.

45. Kislenko GS, Karotkov LuS, Smakov LV. The meadow tick Dermacentor reticulatus in natural foci of tick-borne encephalitis in Udmurtia. Parazitologiya. 1987;21:730-5.

46. Hornok S. Dermacentor reticulatus (Fabricius, 1794). In: Estrada-Peña A Mihalca A, Petney T, editors. Ticks of Europe and North Africa. Cham, Switzerland: Springer; 2017. p. 287-92.

47. Obiegala A, Król N, Oltersdorf C, Nader J, Pfeffer M. The enzootic life-cycle of Borrelia burgdorferi (sensu lato) and tick-borne rickettsiae: an epidemiological study on wild-living small mammals and their ticks from Saxony, Germany. Parasit Vectors. 2017;10:115.

48. Bestehorn M, Weigold S, Kern WV, Chitimia-Dobler L, Mackenstedt U, Dobler G, Borde JP. Phylogenetics of tick-borne emcephalitis virus in endemic foci in the upper Rhine region in France and Germany. PLoS One. 2018;13:e0204790.

49. Weidmann M, Frey S, Freire CC, Essbauer S, Ruzek D, Klempa B, et al. Molecular phylogeography of tick-borne encephalitis virus in central Europe. J Gen Virol. 2013;94:2129-39. 